\title{
ANÁLISE DA PRESERVAÇÃO DOS RECURSOS HÍDRICOS POR MEIO DE IMAGEM DE SATÉLITE
}

\author{
Fernanda Leite Ribeiro ${ }^{1}$ \\ Gabriel Rondina Pupo da Silveira² \\ William Renan Piva dos Santos ${ }^{3}$
}

\section{RESUMO}

O trabalho visou obter o uso do solo da microbacia Ribeirão Couro-de-Boi, município de Uraí e Jataizinho, Paraná, a partir da utilização de imagem de satélite, a determinação das Áreas de Preservação Permanentes (APPs) e de conflitos. Para a elaboração destes mapas foram utilizados o Sistema de Informações Geográficas IDRISI Selva e o software CartaLinx. As bases cartográficas utilizadas foram as cartas planialtimétricas digitais de Assaí e Uraí, em escala 1:50.000, e a imagem de satélite digital, bandas 5, 4 e 3 do sensor Thematic Mapper do LANDSAT - 5. O software IDRISI Selva foi utilizado para o georreferenciamento da imagem, geração dos buffers de APPs e o overlay para obtenção dos conflitos de uso além da confecção do mapa temático final. No CartaLinx feito a delimitação da área de estudo e delimitação dos elementos (limite, da rede de drenagem e das áreas de uso e cobertura). O mapa de uso solo da microbacia mostrou que o uso cultura foi à classe que com maior ocorrência na microbacia $57,32 \%$ (1425,51 ha) e que no mapa de APPs o uso cultura corresponde a somente $35,06 \%$ (152.91 ha) da área, sendo o restante estão sendo usados para outros fins.

PALAVRAS-CHAVE: Áreas de preservação permanente. Áreas de conflito. IDRISI- Selva.

\section{ANALYSIS OF THE PRESERVATION OF WATER RESOURCES SATELLITE IMAGE MEDIA}

\section{ABSTRACT}

The study aimed to obtain the land use of the watershed Ribeirão Couro-de- Boi, located in the cities of Uraí and Jataizinho, Paraná state, using satellite image to determine the Permanent Preservation Areas and the use conflict. For the preparation of these maps was used Geographic Information System - GIS - IDRISI Selva and the software CartaLinx. The cartographic databases used were digital planialtimetrics letters of Assaí and Uraí in scale 1: 50,000, and the digital satellite image, bands 5, 4 and 3 Thematic Mapper sensor of Landsat - 5. The IDRISI Selva software was used for

\footnotetext{
${ }^{1}$ Engenheira Florestal, Universidade Estadual de Londrina, Docente. E-mail: flribeiro@yahoo.com.

2 Mestrando em Energia na Agricultura-FCA, Unesp Botucatu, SP. E-mail: gabrielrondina@hotmail.com

3 Discente em bacharelado em Geografia - Universidade Estadual de Londrina. E-mail: william.piva@hotmail.com
} 
georeferencing image, generation of Permanent Preservation Areas buffers and the overlay to obtain the conflict of use, and to generate the final thematic map. The software CartaLinx was used in the delimitation of the study area and delineation of the elements (limit of the drainage network and areas of use and coverage). The map of the watershed land use showed that use culture was the class with the highest occurrence in the watershed $57.32 \%$ (1425.51 ha) and the map of APPs using culture represents only $35.06 \%$ ( $152.91 \mathrm{ha}$ ) of the area, the remainder being used for other purposes.

KEYWORDS: Permanent preservation areas. Conflict areas. IDRISI- Selva.

\section{ANÁLISIS DE LA CONSERVACIÓN DE LOS RECURSOS HÍDRICOS SATELITE MEDIA IMAGEN}

\section{RESUMEN}

El estudio tuvo como objetivo obtener el uso del suelo de la cuenca Ribeirão cuero de Boi, municipio de Uraí y Jataizinho, Paraná, de la imagen de satélite de uso, la determinación de las Áreas de Preservación Permanente (PPA) y los conflictos. Para la elaboración de estos mapas se utilizó Sistema de Información Geográfica IDRISI Selva y software CartaLinx. Las bases de datos cartográficos utilizados fueron planialtimetrics cartas digitales de Assam y Uraí en escala de 1: 50.000 , y la imagen de satélite digital, bandas 5, 4 y 3 del sensor Thematic Mapper de Landsat - 5 software IDRISI Selva se utilizó para imagen georeferenciación, generación de tampones PPA y la superposición para obtener el uso de los conflictos más allá de hacer el mapa temático final. En CartaLinx realizado la delimitación de la zona de estudio y trazado de los elementos (límite de la red de drenaje y áreas de uso y cobertura). El mapa de la utilización del suelo de cuencas mostró que el uso de la cultura era la clase con la más alta incidencia en la cuenca del $57,32 \%(1.425,51 \mathrm{ha})$ y el mapa de aplicaciones usando la cultura representa sólo el 35,06\% (152,91 hectáreas) de la zona, y el resto se utiliza para otros fines.

PALABRAS CLAVE: áreas de preservación permanente. Zonas de conflicto. IDRISI- Selva

\section{INTRODUÇÃO}

Ao passar dos anos os estudos ambientais se tornaram importantes, pela necessidade de garantir um planeta adequado para as gerações futuras, sobretudo, as bacias hidrográficas se tornam importantes recortes espaciais, no que se refere a meio ambiente. Como afirmou Rocha (1991), é aconselhável que um programa que vise à conservação dos recursos naturais inicie seus trabalhos pelas unidades naturais.

Um dos pontos críticos da degradação é a destruição de florestas, sendo o desmatamento o principal causador dessa destruição, sendo que as áreas desmatadas correspondem à metade das matas nativas do mundo.

A partir do diagnóstico local, podemos reconhecer áreas com manejo inadequado do solo, através do uso irresponsável de agrotóxicos e da destruição da 
cobertura florestal, bem como as matas ciliares, resultando na desertificação em algumas áreas do planeta.

A falta de um planejamento racional de uso da terra, seja pela falta de conhecimento, seja pela necessidade dos agricultores, tem promovido diversos impactos negativos, muitas vezes chegando a limites críticos em determinadas regiões, resultando em degradação ambiental e redução da qualidade de vida, não só para a comunidade rural, mas também para toda população, segundo Dent e Young (1993).

O manejo das bacias hidrográficas visa recuperar a bacia, regularizando o seu fluxo de água, diminuindo a erosão e, por conseguinte o assoreamento do rio principal e seus afluentes, fornecendo água de boa qualidade e em abundância para irrigação, principalmente na época de estiagem. A erosão, consequência do desmatamento depredatório, desequilibra o ecossistema causando prejuízos irrecuperáveis a curto e médio prazo. A recuperação ecológica da bacia somente é possível através do seu manejo correto e planejado (ROCHA, 2001).

A preservação das APP é de fundamental importância na gestão de bacias hidrográficas, pois contribuem para a estabilidade dos ciclos hidrológicos e biogeoquímicos visando a dar condições de sustentabilidade à agricultura.

Intervenções nas APP para abertura de novas áreas agrícolas comprometerá, no futuro, a reposição de água nos aquíferos, a qualidade de água superficial e subterrânea, perda de solo, ameaças à saúde humana e degradação dos mananciais, além de comprometer a produção de alimentos.

O papel regulador dos ciclos naturais realizado pelas APP é fundamental para a manutenção do sejam elas várzeas ou "florestas ripárias - e os topos de morro ocupados por campos de altitude ou rupestres são áreas insubstituíveis em razão da biodiversidade e de seu alto grau de especialização e endemismo, além dos serviços ecossistêmicos essenciais que desempenham - tais como a regularização hidrológica, a estabilização de encostas, a manutenção da população de polinizadores e de ictiofauna, o controle natural de pragas, das doenças e das espécies exóticas invasoras. Na zona ripária, além do abrigo da biodiversidade com seu provimento de serviços ambientais, os solos úmidos e sua vegetação nas zonas de influência de rios e lagos são ecossistemas de reconhecida importância na atenuação de cheias e vazantes, na redução da erosão superficial, no 
condicionamento da qualidade da água e na manutenção de canais pela proteção de margens e redução do assoreamento (SILVA et al., 2011).

O entendimento da importância da manutenção de áreas naturais como Áreas de preservação permanentes (APPs) e reservas legais (RLs) na propriedade rural é fundamental, já que existe a concepção errônea de que as áreas com vegetação nativa representam áreas não produtivas, de custo adicional, sem nenhum retorno ao produtor. Essas áreas, a rigor, são fundamentais para manter a produtividade em sistemas agropecuários, tendo em vista sua influência direta na produção e conservação da água, da biodiversidade, do solo, na manutenção de abrigo para agentes polinizadores, para dispersores e para inimigos naturais de pragas das próprias culturas da propriedade (SILVA et al., 2011).

A problemática das áreas de conflito nas Áreas de Preservação Permanente, ou seja, a ausência de matas ciliares nas APPs existe desde os primórdios períodos de iniciativa agrícola em nosso país. Devido à grande preocupação com o meio ambiente está ocorrendo uma 'conscientização ambiental' capaz de modificar a legislação e impor respeito à natureza através das modificações nas leis, porém, é muito difícil fiscalizar pessoas/órgãos que não respeitam estas leis, e destroem as matas nativas, incluindo às APPs.

Um dos grandes desafios do homem para a conservação ambiental é concentrar esforços e recursos para preservação e recuperação de áreas naturais consideradas estratégicas, das quais vários ecossistemas são dependentes. Dentre essas, destacam-se as Áreas de Preservação Permanentes (APPs), que tem papel vital dentro de uma microbacia, por serem responsáveis pela manutenção e conservação dos ecossistemas ali existentes (MAGALHÃES e FERREIRA, 2000), sendo elas a fauna e flora terrestre e aquática. Estas foram instituídas na lei afim de que se estabeleça uma proteção ambiental de modo natural ao entorno dos canais de drenagem.

As Áreas de Preservação Permanente são responsáveis também, pela conservação do meio físico, no que se refere à inibição dos efeitos erosivos, a lixiviação de nutrientes do solo e promovendo a diminuição do assoreamento dos canais de drenagem, ocasionando a regularização da vazão de água dos canais.

Nos últimos tempos, com toda a problemática ambiental e a percepção do homem em relação às suas atitudes errôneas em relação ao meio ambiente, 
surgiram às pressões sociais para que hajam políticas públicas voltadas para os recursos hídricos. Existe uma preocupação muito grande com a qualidade e a quantidade da água para suprir a demanda, que está cada vez maior devido ao aumento da população mundial (TAUK-TORNISIELO et. al., 1995). Desta forma, o levantamento de estudos da ecologia da paisagem local é de suma importância, segundo Alves (2009), é uma técnica de estudos, que pode ser interpretada como a análise das circunstâncias provocadas nas estruturas da paisagem pela influência humana e pelo uso do solo. Os métodos de pesquisa aplicados na ecologia da paisagem são imagem de satélites e fotos aéreas. Para Dainese (2001), o interesse dos usuários pelos dados orbitais é devido à disponibilidade de dados e a facilidade no levantamento de campo, que diminui as dúvidas de interpretação. Para Rodrigues (2000), o uso deste tipo de ferramenta, pode auxiliar no planejamento e ocupação ordenada e lógica do meio físico, bem como a permissão de avaliar e monitorar a preservação de áreas naturais.

Dentro deste contexto, fazem-se necessários estudos relacionados à preservação das Áreas de Preservação Permanente, o que indica a importância deste trabalho, que busca identificar através de mapas, locais que estão suscetíveis a degradação ambiental, ou seja, as áreas próximas aos canais de drenagem que não possuem matas e foram transformadas em espaço de produção agropecuária, em alguns casos, são locais utilizadas para moradia devido à deficiência de um planejamento urbano adequado, ocasionando áreas de risco ambiental e social.

O mapa de áreas de conflito permite a visualização da degradação ambiental existente, favorecendo o conhecimento da área para futuras interferências no zoneamento ecológico da região estudada.

\section{OBJETIVOS}

No presente trabalho foram mapeadas as áreas de uso do solo, de Preservação Permanente (APPs) e de conflitos da microbacia Ribeirão Couro-deBoi, município de Uraí e Jataizinho, Paraná. 


\section{MATERIAIS E MÉTODOS}

A microbacia do Ribeirão Couro-de-boi localiza-se nos municípios de Uraí e Jataizinho (PR) e encontra-se localizada entre as coordenadas UTM, longitudes 508000 a $518000 \mathrm{~m} \mathrm{~W}$ e latitudes 7422000 a $7430000 \mathrm{~m} \mathrm{~S}$, com uma área de 2487,15 ha (Figuras 1 e 2).

Figura 1. Localização da microbacia Ribeirão Couro-de-Boi, município de Uraí e Jataizinho, Paraná.

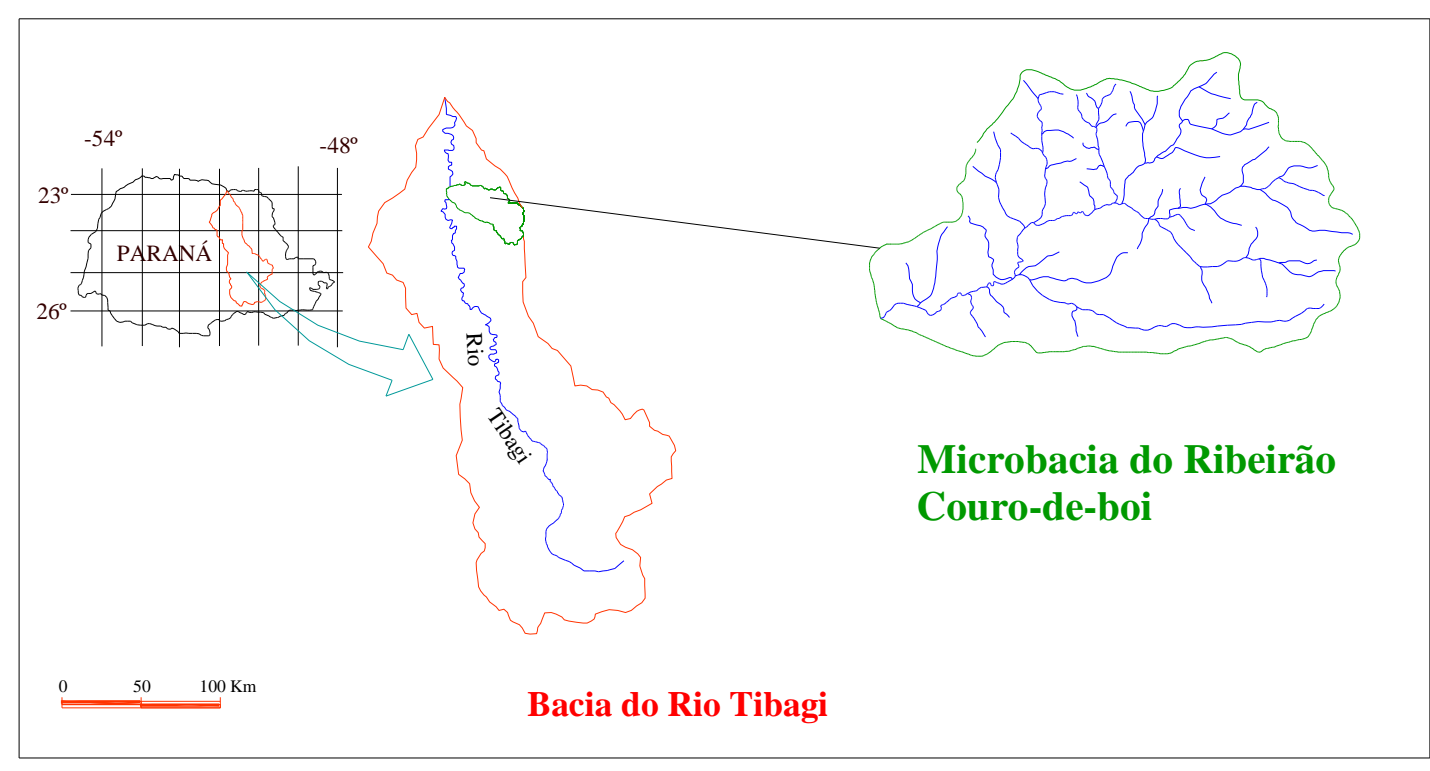

Segundo dados da carta de solos do Estado do Paraná (FOLHA SF-22-Z-CI-3 MIR 497), elaborado pela EMBRAPA (2007) constatam-se que na bacia do Ribeirão Coqueiro são encontrados os seguintes tipos de solos: NEOSSOLO REGOLÍTICO Eutrófico (RRe 10), NITOSSOLO VERMELHO Eutroférrico (NVef 3).

Os pontos de controle (coordenadas) para o georreferenciamento e os pontos de máxima altitude para digitalização do limite da microbacia tiveram como base as Cartas Planialtimétricas elaboradas pelo IBGE (1991), em formato digital. As cartas utilizadas foram Assaí (MI-2759-3) e Uraí (MI-2759-1), em escala 1:50.000, com curvas de nível de 20 em 20 metros.

Os dados foram processados em um microcomputador Pentium, $500 \mathrm{MHz}$, HD 13,0 Gb, $128 \mathrm{Mb}$ de memória RAM, com saída para impressora a jato de tinta HP Deskjet 695 C.

Foi utilizado o Sistema de Informações Geográficas - IDRISI Selva para o processamento das informações georreferenciadas, para a conversão dos dados 
vetoriais em imagem raster, na elaboração do mapa de uso e conflito da terra e de áreas de Preservação Permanente (APPs).

O software CartaLinx foi utilizado na digitalização do limite da microbacia, da rede de drenagem e das áreas de cobertura vegetal, obtidas através de imagens de satélite.

O limite da área de estudo foi determinada pelo divisor topográfico, sendo este responsável por fixar a área da qual provém o deflúvio superficial da microbacia. O divisor de água é uma linha que representa os limites da bacia, determinando o sentido de fluxo da rede de drenagem e a própria área de captação da bacia hidrográfica. segundo Villela e Mattos (1975). A área foi definida a partir das cartas planialtimétricas editadas pelo Instituto Brasileiro de Geografia e Estatística - IBGE em 1991, folha Assaí (MI-2759-3) e Uraí (MI-2759-1), em escala 1:50.000, com curvas de nível de 20 em 20 metros.

Inicialmente $o$ arquivo que contêm a carta planialtimétrica foi importado para o IDRISI em formato vetorial. Esse arquivo foi georreferenciado e com o auxílio do software CartaLinx feito a delimitação da área de estudo.

Para a elaboração do mapa de uso do solo foi usada uma imagem de satélite digital, bandas 5, 4 e 3 do sensor Thematic Mapper do LANDSAT - 5, da órbita 222, ponto 76, passagem de 2011, disponível no site do INPE ( Instituto Nacional de Pesquisas Espaciais). A partir desta imagem foi elaborada uma composição colorida, usando o Software IDRISI Selva, com a combinação das bandas 3, 4 e 5, pois esta apresenta uma boa discriminação visual dos alvos, possibilitando a identificação dos padrões de uso da terra de maneira lógica. Esta composição apresenta os corpos d'água em tons azulados, as florestas e outras formas de vegetações em tons esverdeados e os solos expostos em tons avermelhados.

Para obter a composição da imagem RGB (Red Green Blue) foi utilizando a função Composite do menu "Display" do software IDRISI. Em seguida foi feito o georeferenciamento da composição, através do módulo Reformat/Resample do IDRISI, utilizando os pontos de controle obtidos nas cartas planialtimétricas do IBGE, referentes aos município de Uraí e Assaí. Para o georreferenciamento da composição foi utilizado um arquivo de ponto de controle obtido a partir da imagem de satélite e outro a partir das cartas topográficas de Uraí e Assaí, as quais já foram 
georreferenciadas anteriormente. Desta forma, as coordenadas de cada ponto foram determinadas e com estes dados foi feito um arquivo de correspondência o qual foi usado para georreferenciar a nova imagem. .Os arquivos estão de acordo com o sistema de coordenadas planas, projeção UTM, datum SAD-69.

Após o georreferenciamento foi feito o recorte da imagem através da opção Reformat/Window extraindo assim apenas a área da microbacia. $O$ arquivo foi importado para o software CartaLinx através do comando File/ Image Conversion.

Em seguida, através do comando File/New Coverage/Coverage Based Upon Bitmap foi aberto este arquivo para iniciar o processo de delimitação dos elementos (limite, da rede de drenagem e das áreas de uso e cobertura), sendo usados polígonos para identificar as áreas de uso e cobertura e linhas para a rede de drenagem. Para a identificação dos polígonos foi criada uma tabela, através do menu Tables/Add Fields, onde cada polígono recebeu um número correspondente ao elemento que representa (Ex: Mata Ciliar $=1$, Culturas $=2$, e assim sucessivamente) e então estes arquivos foram exportados para o IDRISI e transformados em imagem raster. No IDRISI, através do comando Área do menu Database Query, pertencente ao módulo Analysis, foram determinadas as áreas e as porcentagens de cada uso.

Foram definidas as Áreas de Preservação Permanentes ao longo dos cursos d'água e ao redor das nascentes da microbacia do Córrego Couro-de-Boi, utilizando a operação Gis analysis através do comando Distance operators/Buffer do Idrisi, a qual proporcionou a criação de um buffer de $50 \mathrm{~m}$ de raio nas áreas das nascentes e um buffer de $30 \mathrm{~m}$ de cada lado da drenagem ao longo do córrego, resultando no mapa de APPs, fundamentado na Lei Florestal oㅜ 12.727, de 17 de outubro de 2012, que considera essas áreas, cobertas ou não por vegetação nativa: "com a função ambiental de preservar os recursos hídricos, a paisagem, a estabilidade geológica e a biodiversidade, facilitar o fluxo gênico de fauna e flora, proteger o solo e assegurar o bem-estar das populações humanas". Os buffers referentes às nascentes e aos cursos através da opção Mathematical operators/Gis Analysis/Overlay gerando o mapa final de Áreas de preservação Permanente (APPs).

O mapa de conflitos mostra que as áreas ocupadas pelos usos do solo estão em desacordo com a Legislação Florestal vigente, ou seja, as áreas de APPs que deveriam estar cobertas por vegetação nativa estão sendo usadas por outra 
atividade agrícola. Para identificar e quantificar as áreas de conflito foi utilizada a álgebra de mapas, presentes no SIG IDRISI, onde foram cruzados o mapa de uso de solo com o mapa final das APPs.. Foram utilizados a opção Mathematical operators do menu Gis Analysis com o comando Database Query/Overlay. O mapa de conflitos de uso da terra foi gerado a partir desta sobreposição e as áreas conflitantes foram medidas usando a operação Database Query/Area.

\section{RESULTADOS E DISCUSSÃO}

No mapa final de uso do solo (figura 2) foram identificadas 6 classes que compreendem vegetação natural, culturas, pastagem, reflorestamento, fruticultura e lagos/represas.

Figura 2. Usos e ocupações na microbacia Ribeirão Couro-de-Boi, município de Uraí e Jataizinho, Paraná.

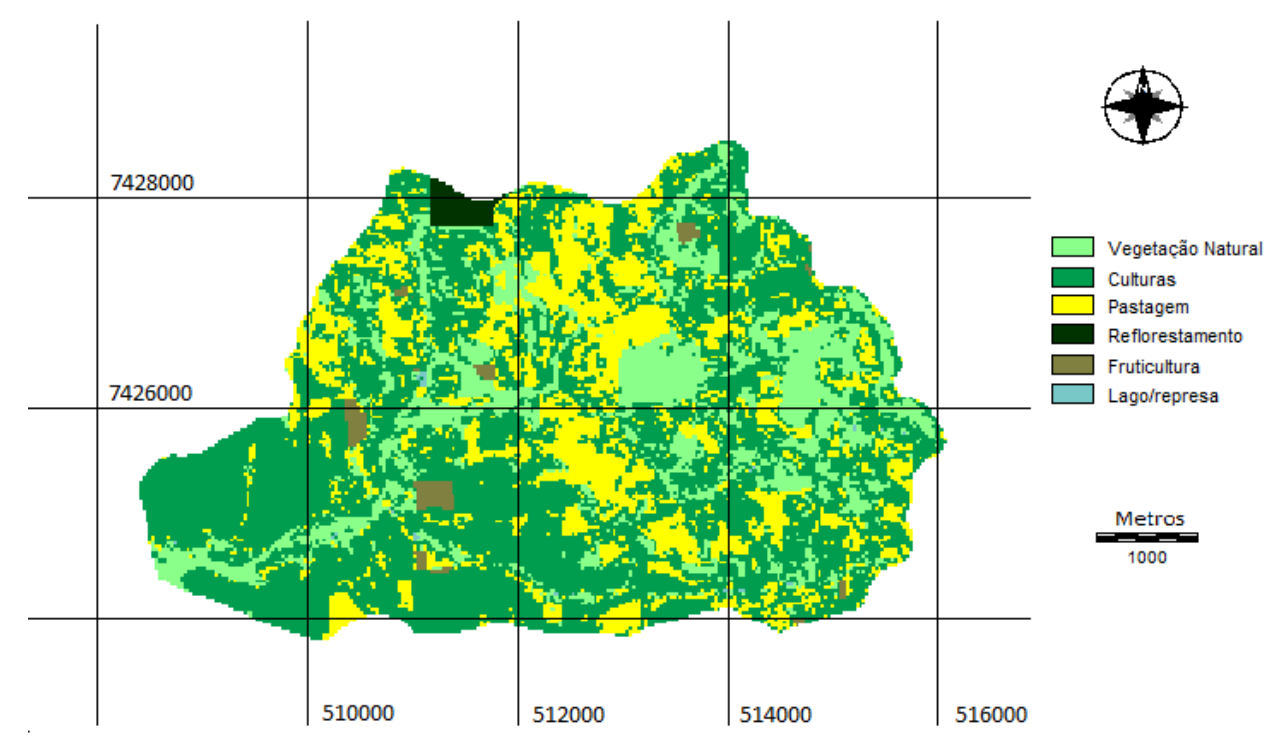

$\mathrm{Na}$ tabela 1 encontram-se informações retiradas do mapa acima (figura 2) e contém os valores em hectares e porcentagens de cada classe de uso do solo em relação à área total da bacia. 
Tabela 1. Áreas totais em hectares e porcentagens relativas às classes de uso na microbacia Ribeirão Couro-de-Boi, município de Uraí e Jataizinho, Paraná.

\begin{tabular}{lcc}
\hline Classes de uso da Terra & Área (ha) & $\%$ \\
\hline Vegetação Natural & 448,20 & 18,02 \\
Culturas & 1425,51 & 57,32 \\
Pastagem & 561,42 & 22,57 \\
Reflorestamento & 20,25 & 0,81 \\
Fruticultura & 28,62 & 1,15 \\
Lagos e represas & 3,15 & 0,13 \\
\hline Total & $\mathbf{2 4 8 7 , 1 5}$ & $\mathbf{1 0 0}$ \\
\hline
\end{tabular}

Foi observado que a microbacia acima (Figura 2 e Tabela 1) está sendo ocupada por vegetação natural (448,20 ha), culturas (1425,51 ha), pastagem $(561,42 \mathrm{ha})$, reflorestamento $(20,25 \mathrm{ha})$, fruticultura $(28,62 \mathrm{ha})$, e com lagoas/represas (3,15 ha). Segundo os dados observou-se que o uso "culturas" predomina na região, mais de $50 \%$ da área em estudo.

A cobertura florestal em áreas definidas como Áreas de Preservação Permanente constitui-se em elemento de extrema importância na manutenção da qualidade ambiental, desempenhando diversas funções entre elas, a dissipação da energia do escoamento superficial, a proteção das margens dos cursos d'água, a estabilização de encostas, a proteção de nascentes, o impedimento do assoreamento de corpos d'água, o abastecimento do lençol freático, captura e retenção de carbono, porém, tais funções muitas vezes ficam comprometidas, decorrente de sua falta (GARCIA, 2011).

Segundo JACOVINE et al. (2008) existe uma barreira forte ao cumprimento da lei pelos agricultores pois uma porção significativa da propriedade ocupada pelas áreas de preservação permanente e de reserva legal, aliada ao fato de que as APPs de margens de cursos d'água e em torno de nascentes ocupam a parte mais produtiva da propriedade, principalmente em regiões caracterizadas por relevo montanhoso e com marcante presença de nascentes e cursos d'água. 
Figura 2. Rede de drenagem da microbacia Ribeirão Couro-de-Boi, município de Uraí e Jataizinho, Paraná.

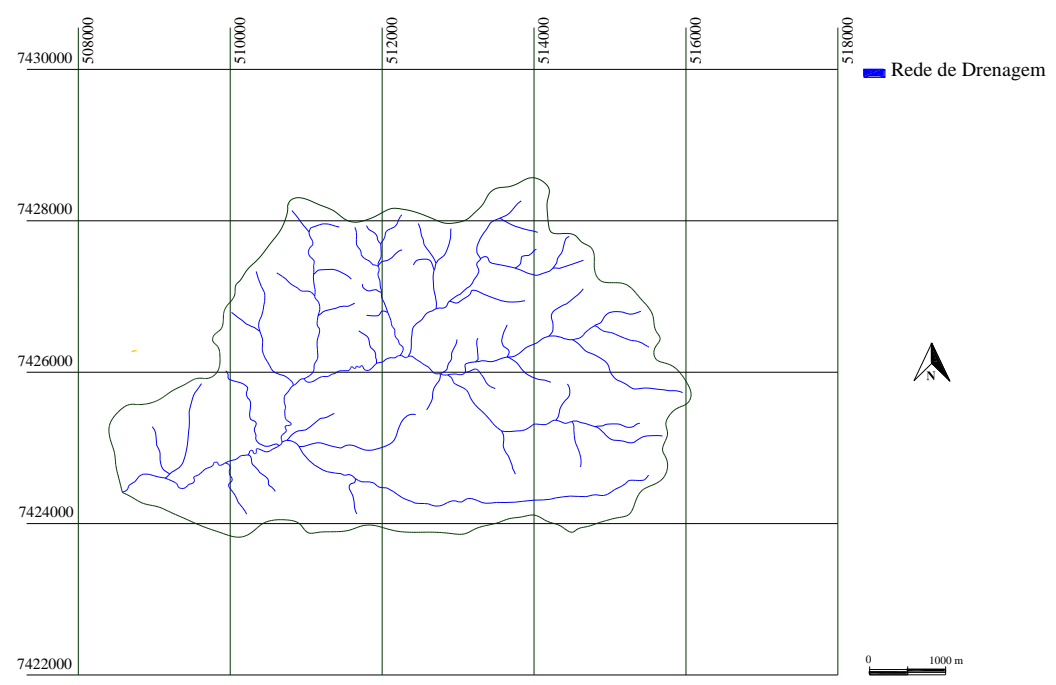

A partir da rede de drenagem da microbacia (Figura 3) foram mapeadas as APPs em um raio de 50 metros para as nascentes e de $30 \mathrm{~m}$ de cada lado para os rios, pois estes são estreitos e não ultrapassam 10 metros de largura, segundo à legislação vigente presente no Código Florestal, conforme podemos observar na Figura 3.

Figura 3. APPs da microbacia Ribeirão Couro-de-Boi, município de Uraí e Jataizinho,

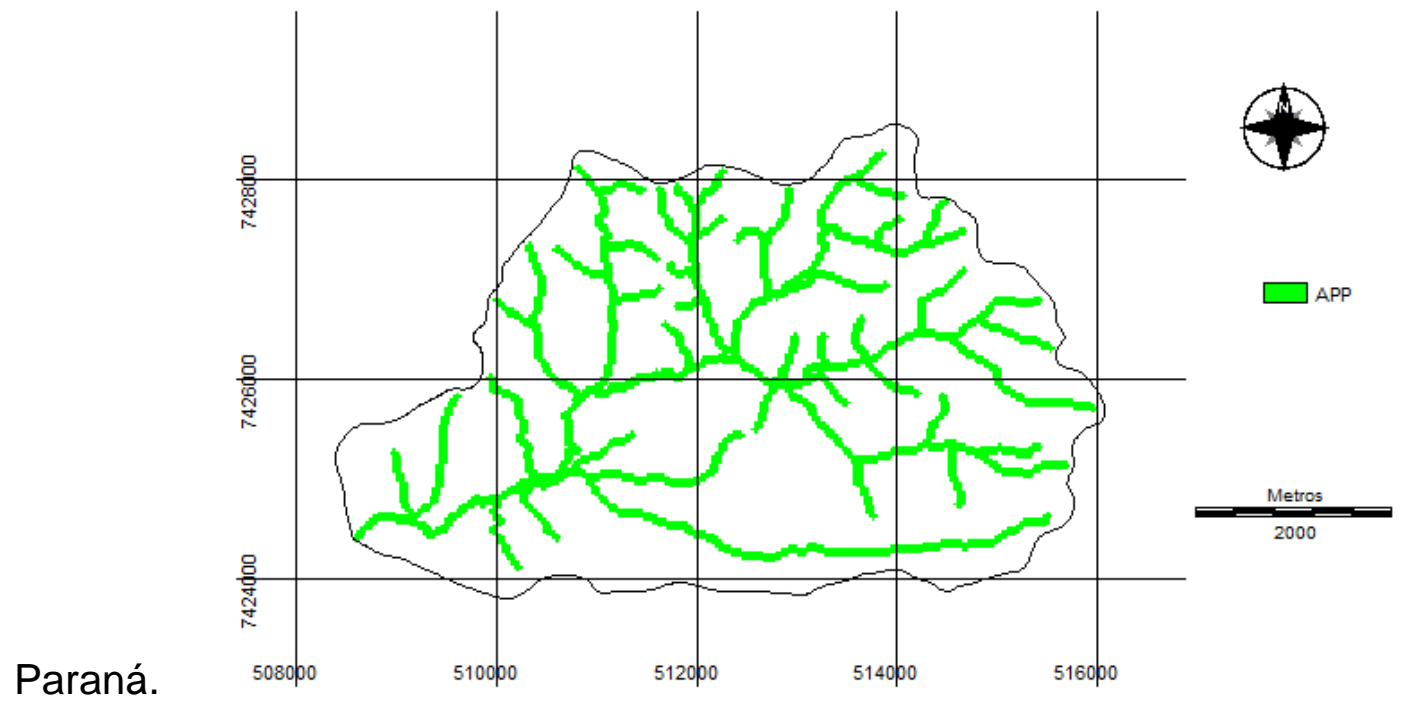

As Áreas de Preservação Permanente, segundo Legislação Florestal, não podem ser ocupadas por outros usos, porém foi observado na Figura 4 e Tabela 2, que nas APPs as vegetações nativas foram substituídas por pastagens, culturas, reflorestamento e fruticultura. Da área total das APPs, apenas $35.06 \%$ estão sendo 
usadas e preservadas corretamente. As matas ciliares vêm sendo alvo das atividades antrópicas, diante dos interesses conflitantes de uso e ocupação da terra, ocasionando a sua supressão ao longo dos cursos d'água, como é o caso da microbacia Ribeirão Couro-de-Boi no qual sua utilização é para fins agropecuários.

Figura 4 - Conflitos em Áreas de Preservação Permanente na microbacia Ribeirão Couro-de-Boi, município de Uraí e Jataizinho, Paraná.

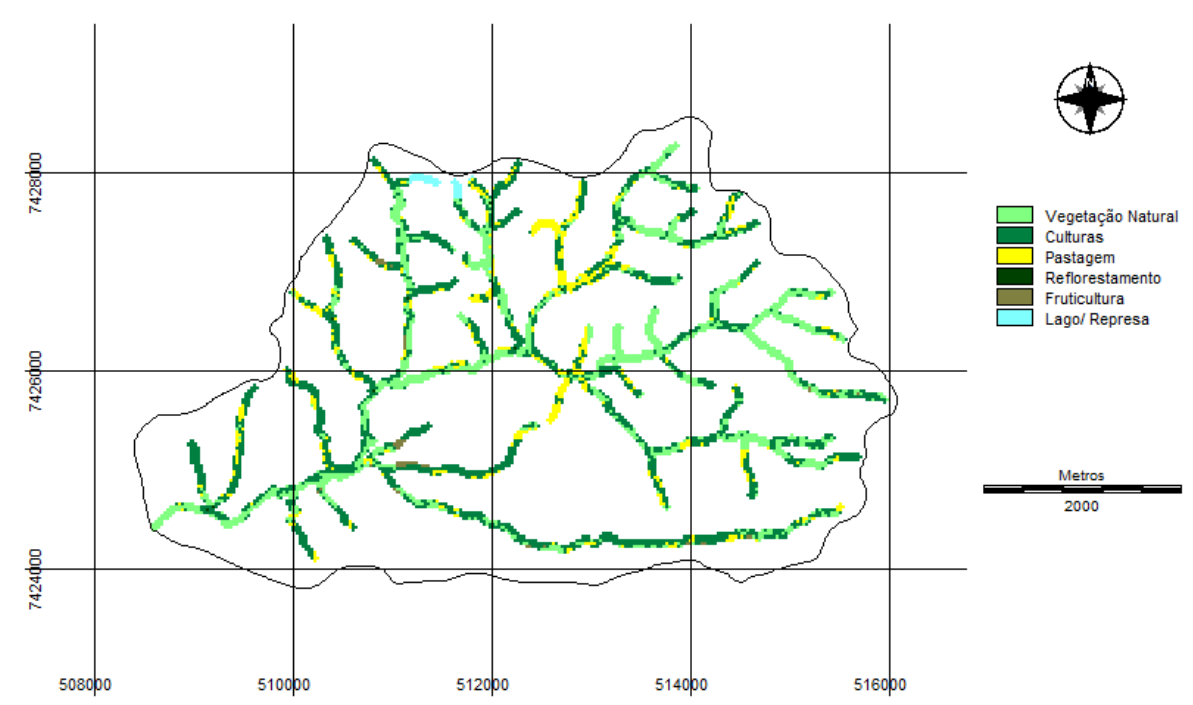

Tabela 2 - Áreas de Preservação Permanente e de conflitos em APPs (ha e \%).

\begin{tabular}{lcccc} 
Classes de uso da Terra & \multicolumn{2}{c}{ APPs } & \multicolumn{2}{c}{ Conflitos } \\
& (ha) & $\%$ & (ha) & $\%$ \\
\hline Vegetação Natural & 152.91 & 35,06 & - & - \\
Culturas & 215.82 & 49,48 & 215.82 & 76,20 \\
Pastagem & 57.60 & 13,21 & 57.60 & 20,34 \\
Reflorestamento & 5.22 & 1,20 & 5.22 & 1,84 \\
Fruticultura & 2,52 & 0,58 & 2,52 & 0,89 \\
Lagos/Represas & 2,07 & 0,47 & 2,07 & 0,73 \\
\hline Total & $\mathbf{4 3 6 , 1 4}$ & $\mathbf{1 0 0}$ & $\mathbf{2 8 3 , 2 3}$ & $\mathbf{1 0 0}$
\end{tabular}

Analisando os dados acima (Tabela 2) conclui-se que a área de estudo deve ser recomposta 283,83 hectares de Área de Preservação Permanente. Na Tabela 2 foram observadas as áreas e a porcentagem das áreas de conflito nas APPs. $\mathrm{Na}$ microbacia estudada foi encontrado a área de conflitos de usos "culturas", com 76,20 
$\%$ (215.82 ha) e de "pastagem" em 20,34 \% (57.60 ha), totalizando 96,54 \% (273,42) da área com esses usos e os demais abrangem 9,81\% (3,46 ha) dessa área.

O Sistema de Informações Geográficas IDRISI permitiu que fossem quantificados e caracterizados os usos do solo, as Áreas de Proteção Permanente e de conflito, desta forma, foi possível identificar a situação de usos da microbacia que estão em conflito com a legislação ambiental, sendo que o uso inadequado e sem planejamento da terra torna-o infértil de maneira irreversível, provocando a baixa produtividade das culturas.

\section{CONCLUSÃO}

A microbacia Ribeirão Couro-de-Boi apresentou problemas ambientais decorrentes do uso antrópico indevido, muito presente na região, principalmente relacionado à retirada da cobertura vegetal para o uso agropecuário indiscriminado.

O mapa de uso solo da microbacia mostrou que o uso cultura foi a classe que com maior ocorrência na microbacia 57,32 \% (1425,51 ha) e que no mapa de APPs o uso cultura corresponde a somente $35,06 \%$ (152.91 ha) da área, sendo o restante ocupado por usos indevidos do solo.

As técnicas de sensoriamento remoto e geoprocessamento foram ferramentas úteis para a avaliação da microbacia estudada, permitindo observar de forma rápida e eficaz seu uso indevido, podendo assim, ter um melhor direcionamento nas ações preventivas e corretivas do local. Desta forma, podemos ressaltar que com a grande expansão das atividades humanas sobre o ambiente, a demanda por essas tecnologias tem sido cada vez mais procurada.

Neste trabalho observou-se a importância do estudo da bacia hidrográfica como unidade de gerenciamento territorial para a conservação dos recursos naturais.

Serão necessários mais levantamentos na área da microbacia para promover o seu uso racional e obter um desenvolvimento sustentável na região, usando racionalmente os recursos hídricos e o solo, diminuindo assim a degradação do meio ambiente. 
As Áreas de Proteção Ambiental devem ser respeitadas, segundo o Código Florestal, para a preservação dos recursos hídricos e do meio ambiente, proporcionando uma melhor qualidade melhor para todos.

\section{REFERÊNCIAS BIBLIOGRÁFICAS}

ALVES, T.L. Fragmentos florestais na área da bacia hidrográfica do Ribeirão Taquara: uma análise pelo caminha e Geo-foto-grafar. 2009. 125 p. Dissertação (Mestrado em Geografia, Meio ambiente e Desenvolvimento) - Universidade de Londrina, Londrina, 2009.

DAINESE, R. C. Sensoriamento remoto e geoprocessamento aplicado ao estudo temporal do uso da terra e na comparação entre classificação não supervisionada e análise visual. Botucatu, 2001. Dissertação (mestrado) - Faculdade de Ciências Agronômicas, Universidade Estadual Paulista.

DENT, D.; YOUNG, A. Soil survey and land evaluation. London: E \& FN Spon, 1993. 292p.

EMBRAPA - EMPRESA BRASILEIRA DE PESQUISA AGROPECUÁRIA. Mapa de Solos do Estado do Paraná. Rio de Janeiro: Documentos 96, 2006, 73p.

GARCIA, Y. M. Aplicação do Código Florestal como Subsídio para o Planejamento Ambiental na Bacia Hidrográfica do Córrego do Palmitalzinho - Regente Feijó - SP. Trabalho de conclusão (bacharelado - Geografia) - Universidade Estadual Paulista, Faculdade de Ciências e Tecnologia, Presidente Prudente, 2011.

IBGE. Instituto Brasileiro de Geografia e Estatística. Carta topográfica: Assaí (MI-2759-3). Serviço gráfico do IBGE, 1991. Escala 1:50.000.

IBGE. Instituto Brasileiro de Geografia e Estatística. Carta topográfica: Uraí (MI-2759-1). Serviço gráfico do IBGE, 1991. Escala 1:50.000.

JACOVINE, L. A. G.; CORRÊA, J.B.L.; SILVA, M.L.; VALVERDE, S.R.; FERNANDES FILHO, E.I.; COELHO, F.M.G.; PAIVA, H.N. Quantificação das áreas de preservação permanente e de reserva legal em propriedades da bacia do Rio Pomba-MG. Rev. Árvore [online]. 2008, vol.32, n.2, pp. 269-278. ISSN 0100-6762.

MAGAlHÃES, C. S.; FERREIRA, R. M. Áreas de Preservação Permanente em uma microbacia. Informe Agropecuário, Belo Horizonte. V.21, n.207, p. 33-39, 2000.

ROCHA, J. S. M. Manual de manejo integrado de bacias hidrográficas. Santa Maria: Edições UFSM, 1991, p.181.

RODRIGUES, A. C. M. Mapeamento multitemporal do uso e cobertura do solo do município de São Sebastião - SP, utilizando técnicas de segmentação e classificação de imagens TMLandsat e HRV-SPOT. São José dos Campos: INPE, 2000.

ROCHA, J.S.M. da; Kurts, S.M.J.M. Manual de manejo integrado de bacias hidrográficas. 4 ed. Santa Maria: UFSM/CCR, 2001. 120p.

SILVA, J. A. A.; NOBRE, A. D.; MANZATTO, C. V.; JOLY, C. A.; RODRIGUES, R. R.; Skorupa, L. A.; NOBRE, C. A.; AHRENS, S.; MAY, P. H.; SÁ, T. D. A.; CUNHA, M. C.; RECH FILHO, E. L. O Código Florestal e a ciência: Contribuições para o diálogo. São Paulo: SBPC: Academia Brasileira de Ciências, 2011. 124p.

TAUK-TORNIELO, S. M. et al. Análise Ambiental: estratégias e ações. São Paulo: T. A. Queiroz; Rio Claro: Centro de Estudos Ambientais, UNESP, 1995. 